\title{
¿OTRA CRISIS FINANCIERA \\ O UN CAMBIO FUNDAMENTAL \\ EN EL CAPITALISMO FINANCIERO?
}

Marco Romero Cevallos 1

Como en anteriores ocasiones, los meses de septiembre y octubre del presente año han sido el periodo en el que ha estallado la acumulación de enormes dificultades en grandes entidades de los mercados financieros en los Estados Unidos; en algunos casos los bancos y otras entidades han quebrado o han debido ser adquiridas por otras, en procesos de concentración de gran magnitud, que han contado con el respaldo del Estado. Esta evolución ha provocado enormes caídas en las bolsas de valores, que se han replicado igualmente en las más importantes plazas financieras internacionales.

Todo lo descrito no es nuevo en absoluto, y muchos han tendido a considerar esos eventos como un accidente circunstancial, que forma parte del funcionamiento normal de la economía mundial. Sin embargo, son muchos más los que han destacado diversos aspectos de la presente crisis financiera, que consideran como especiales o de relevancia histórica, afirmando que estaríamos ante una crisis secular de gran envergadura, que inexorablemente provocará cambios trascendentales y de larga duración en el funcionamiento del capitalismo.

Este breve artículo no pretende de ninguna manera zanjar esta discusión; lo único que queremos es presentar una serie de elementos que nos permitan avanzar hacia la caracterización de la presente crisis, destacar sus particularidades, conocer que generan grandes dudas con respecto a su magnitud y a la profundidad de sus efectos en la economía norteamericana y global, al igual que sobre los impactos negativos que podría generar en los países en desarrollo y en particular en América Latina.

\section{Reflexiones teóricas y conceptuales}

Se ha acumulado suficiente evidencia empírica y analítica en los últimos años, que comprueba que la globalización financiera es el vector

1. Profesor e investigador de la Universidad Andina Simón Bolívar. 


\section{Marco Romero Cevallos}

de la economía mundial que registra las transformaciones más vertiginosas y potencialmente más destructivas, puesto que los efectos que genera la creciente volatilidad de los flujos financieros, así como la velocidad con la que se transmiten sus impactos negativos y desestabilizadores a los diferentes segmentos de los mercados financieros y a los flujos de comercio e inversión, en todas las latitudes, constituyen hoy una verdadera amenaza para la propia economía global.

Esa constatación, que era absolutamente clara desde la segunda mitad de la década de los ochenta, se ha confirmado dramáticamente en los últimos veinte años, con la sucesión de crisis financieras registradas en el mundo ${ }^{2}$. Las crisis son una característica inherente al capitalismo, como una forma de depurar el mercado y de establecer las bases para una nueva fase de acumulación; en el pasado ellas tendían a presentarse usualmente con una periodicidad aproximada de diez años.

Sin embargo, la profunda liberalización financiera iniciada en los años ochenta, en primer lugar en los países desarrollados, pero generalizada luego al resto del mundo, se aceleró vertiginosamente desde los noventas, llevando a los flujos financieros a alcanzar cifras impresionantes. Incluso uno de los artífices y responsables de las políticas norteamericanas que favorecieron esas tendencias, el ex Presidente de la Reserva Federal de los Estados Unidos (FED), Alan Greenspan, llegó a denunciar en diciembre de 1996, lo que calificaba como "la exhuberancia irracional de los mercados financieros", en referencia a la excesiva valoración en las bolsas de valores de los Estados Unidos y a la creencia de que dicha expansión no tenía límites.

Es preciso destacar que la dinámica y el funcionamiento de la globalización financiera no obedecen a ninguna fuerza sobrenatural, ni sólo a la compulsión de los mercados; esos procesos se explican principalmente por las decisiones normativas, regulatorias y de política económica adoptadas primero por los gobiernos de los países del G7 y luego por los demás gobiernos del mundo, orientadas a la reducción de cualquier traba para la libre circulación de los capitales y hacia su desregulación, especialmente iniciadas por la administración

2. Existen estudios que mencionan que en las últimas tres décadas se habrían registrado 130 crisis financieras en igual número de países. Ver, por ejemplo Girón Alicia:“Crisis financieras”, México, 2005. 
¿Otra crisis financiera o un cambio fundamental en el capitalismo financiero?

Reagan, luego del crack de la bolsa de octubre de 1987. Adicionalmente, esa aceleración de los movimientos financieros se vio facilitada por la creciente aplicación de los avances en las nuevas tecnologías de la información y de las comunicaciones (TICs).

La creatividad y la búsqueda de ganancias por parte de los diversos actores financieros privados harán el resto, generando elevados niveles de innovación financiera y el surgimiento de nuevos "productos financieros" (principalmente los derivados y los futuros; al igual que la creciente "titularización", que ofrece nuevos instrumentos financieros, a partir de la agrupación de los certificados originales de todo tipo de operaciones normales de préstamo, entre otros); en consecuencia, el riesgo se incrementa sustancialmente y los instrumentos de cobertura se expanden rápidamente. En la medida en que dichos activos financieros se transan en los mercados globales, se exacerba la vulnerabilidad financiera de empresas, bancos, hogares y por ende de los países, ya que el riesgo se incrementa a medida que las transacciones se alejan e incluso ignoran a las operaciones originales.
Se crea en consecuencia, un mercado verdaderamente global de las finanzas, que restringe severamente los márgenes tanto para las políticas económicas (especialmente para el manejo de los tipos de cambio y de las tasas de interés), como para la gestión de las empresas, puesto que su valoración en los mercados bursátiles y la generación de ganancias para los accionistas, se convierten en las variables decisivas, por sobre su productividad y su posicionamiento en el mercado.

Se impone así una fuerte restricción de rentabilidad, por parte del capital accionario ${ }^{3}$, que se ejerce en forma permanente y lleva al predominio de las inversiones financieras frente a las productivas (expresión actual de la denominada financiarización de las economías, registrada desde los años ochenta), generando además de las burbujas bursátiles y en otros segmentos de los mercados financieros, fuertes presiones para la reducción de costos, que inciden sobre todo en los salarios, ante la amenaza de la deslocalización de segmentos completos de las cadenas de producción (que migran a China, India, o a otros países en desarrollo),

3. Ver Frederick Lordon: "En fin une mesure contre la démesure de la finance, le SLAM!"; en Le Monde Diplomatique, Février 2007. 
con la consiguiente pérdida de empleos.

En una perspectiva más estructural y crítica, esta tendencia se explicaría por los profundos problemas que enfrentan las economías más desarrolladas desde 1973, debido la debilidad del crecimiento económico registrado, en particular en los sectores de la economía real, que se expresa en una baja tasa de inversión y de creación de empleo, dentro de una clara tendencia a niveles excesivos de capacidad instalada en la industria manufacturera, frente a los niveles reducidos de la demanda efectiva, luego de casi dos décadas de estancamiento y aún reducción de los salarios reales (favorecida por la flexibilización laboral y por la competencia global).

Dichas tendencias se han mantenido subyacentes gracias a una expansión sin precedentes de los niveles de endeudamiento, particularmente en los Estados Unidos, cuya expresión son tanto los elevados niveles de los déficit fiscal y de la balanza comercial, como la vertiginosa elevación de los precios de los valores financieros y de las bolsas, aprovechando el crédito barato y mediante diversos mecanismos de manipulación financiera.

En definitiva, en palabras de Brenner, desde comienzos del presente siglo, el mundo desarrollado asiste al "crecimiento más débil de la economía real desde el final de la II Guerra Mundial, en paralelo con la mayor expansión de la economía financiera o virtual de toda la historia de EE. UU."4.

Cabe destacar, sin embargo, que la presencia de crisis en los mercados financieros se ha agudizado en las últimas dos décadas, cuando prácticamente cada tres años se ha registrado algún problema importante ${ }^{5}$; igualmente muchos analistas han destacado la velocidad del contagio y la amplitud con la que se han propaga-

4. Robert Brenner: Una crisis devastadora en ciernes, Enero 2008.

5. Lordon, sólo desde la perspectiva de los mercados más importantes, identifica, por ejemplo las siguientes: el crack de los mercados de acciones en Estados Unidos, en 1987; la quiebra de los bonos basura y la crisis de las cajas de ahorro y préstamo en Estados Unidos, en 1990; el crack del mercado norteamericano de obligaciones en 1994; la crisis asiática e internacional de 1997, seguida luego por las crisis de Rusia y Brasil, en 1998; la explosión de la burbuja Internet y el derrumbe de la "nueva economía", con el desplome del índice de las acciones NASDAQ, entre el 2001 y el 2003; y la presente crisis del mercado inmobiliario por las hipotecas riesgosas. Ver: Lordon Frederick,Quand le finance prend le monde en otage, Le monde Diplomatique, Septembre 2007. 
¿Otra crisis financiera o un cambio fundamental en el capitalismo financiero?

do los efectos de las crisis hacia diversas regiones y mercados del mundo.

Esta tesis se ha comprobado con las enormes pérdidas que registra el segmento de préstamos hipotecarios de baja calificación, de los Estados Unidos, que arrancó en agosto del 2007, y no ha dejado de sorprender, en los últimos meses, por la magnitud que ha alcanzado, al evidenciarse tanto la errónea calificación de riesgos asociada a dichas operaciones, como la rápida difusión de las dificultades hacia los demás segmentos de los mercados financieros, a través de la titularización y los productos derivados, que han transmitido la crisis hacia muy diversas economías como España, Reino Unido, Alemania y otros países europeos, así como a las economías dinámicas del Asia.

Esta crisis, la primera que enfrenta la Unión Europea desde la introducción del euro, ha llevado a discutir sus límites para establecer un fondo de rescate similar al norteamericano, ya que si bien dichas economías están cada vez más interconectadas, la regulación política de las instituciones financieras europeas no está unificada, y es responsabilidad de una diversidad de entidades, que tienden a responder unilateralmente, como ya se ha visto en la crisis actual.

Todo parece indicar que nos encontramos en el inicio de una cri- sis, cuyos efectos recién comienzan a transmitirse hacia todas las economías del mundo, puesto que la reducción del consumo en los Estados Unidos, así como una menor demanda de inversión (factores que han sido los principales impulsores del crecimiento del PIB en los últimos años), recién comienzan a manifestarse; esas tendencias implicarán una recesión económica, con la consiguiente disminución de las importaciones y de la dinámica económica, que repercutirá en las principales economías desarrolladas y en los mercados emergentes, a través de los canales comerciales y financieros tradicionales.

Esas tendencias generan igualmente una menor demanda y creación de nuevos empleos, que retroalimenta los efectos recesivos antes mencionados. Esto ha implicado también una reducción de las remesas que envían los latinoamericanos que han emigrado hacia los Estados Unidos y países europeos, afectando un flujo de recursos cuya importancia es crucial para las economías de varios países de la región, incluso México, puesto que se han convertido desde los años noventa, en su segundo rubro de ingreso de divisas.

Luego de la dramática sucesión de las crisis financieras y monetarias registradas en el mundo desde la 
década de los noventa, y la vasta evidencia acumulada sobre la ineficacia de las instituciones financieras internacionales (IFIs) para prevenir $y$ enfrentar dichos procesos, e incluso su manejo inadecuado, por no decir interesado de esas crisis, debido a la rigidez y esquematismo de su base teórica, que propugnaba la completa liberalización de los mercados financieros $^{6}$, los países han buscado diversas estrategias que les permitan manejarlas en mejor forma.

Entre los elementos de tales estrategias, fundamentalmente en las economías emergentes, se mencionan los siguientes: reducir la vulnerabilidad externa, mediante la acumulación de reservas; una política cambiaria que si bien adoptó regímenes flotantes, en su aplicación tiene un carácter mucho más pragmático, para responder ante eventuales presiones externas, incluyendo una activa participación de los bancos centrales en su regulación; $y$, finalmente la disposición para crear "acuerdos regionales de cooperación monetaria y financiera"7.
Por lo tanto, la poderosa implosión del financiamiento que se está produciendo en los Estados Unidos, en un verdadero "septiembre y octubre negros", es la continuación de la crisis de las hipotecas de alto riesgo que arrancó en agosto de 2007. Ella se manifiesta en la acumulación de quiebras o de adquisiciones de grandes firmas que han sido pilares de Wall Street, así como en los enormes montos destinados por la FED y el Tesoro de los Estados Unidos para salvar al sistema; hasta llegar al mega paquete de 700 mil millones de dólares, aprobado por el Congreso norteamericano, ante las presiones de la administración Bush, para evitar el colapso del financiamiento norteamericano y sus repercusiones en la economía global. Los analistas económicos e incluso el FMI discrepan sobre la fase en la que se encuentra la crisis (lo peor ya pasó o está por venir), al igual que sobre su magnitud: hay algunos que consideran que sería igual o peor que la crisis de 1929, en tanto que otros consideran que hoy existen mecanismos de polí-

6. Ver Romero Cevallos Marco: "Temas del debate sobre la política económica y el desarrollo", en Revista Ecuador Debate No. 50, Agosto 2000, para una presentación amplia del tema.

7. Moreira Cunha André y Julimar Da Silva Bichara: “Globalización financiera y estrategias periféricas: experiencias recientes de América Latina y lecciones desde Asia",en Revista de Economía Mundial, No. 17, 2007. 
¿Otra crisis financiera o un cambio fundamental en el capitalismo financiero?

tica económica que permitirían enfrentarla en mejor forma.

El contenido del gigantesco salvataje propuesto por el régimen de Bush no se aparta de la orientación predominante en su política económica y en el manejo de la guerra en Irak, que ha propiciado una aguda concentración de la riqueza en un reducido número de grandes empresas y en el poder financiero, dentro de la cual les ha entregado enormes intereses y contratos en el abastecimiento militar y en la reconstrucción de ese país, así como a través de sucesivas exoneraciones tributarias.

El mega paquete busca definitivamente socializar las pérdidas de un reducido número de grandes empresas financieras, pasando los costos a los contribuyentes, mientras ellas y sus altos ejecutivos han acumulado enormes ganancias en la fase anterior, en base a un manejo especulativo y excesivamente riesgoso, confiadas en que el Estado vendría en su rescate. En ese sentido, el salvataje es muy semejante a los aplicados a fines de siglo en varios países en desarrollo, principalmente de América Latina.

Existe una creciente oposición en la opinión pública norteamericana y mundial, contra la forma en que el régimen de Bush y otros gobiernos del mundo industrializado están enfrentando los problemas financieros; cada vez son más las voces que exigen que las entidades financieras y sus altos ejecutivos, cuyos ingresos son millonarios, asuman el costo de sus decisiones.

Lo que queda claro, es que estamos ante una crisis de gran magnitud y de un tipo particular, puesto que sus efectos transformarán definitivamente el funcionamiento de los mercados financieros; en primer lugar, su origen radica en los Estados Unidos, como pocas en los años anteriores; en segundo lugar, ha provocado ya la desaparición de la banca de inversión norteamericana, que fue uno de los agentes más dinámicos de la globalización y de la innovación financieras en las dos décadas precedentes; el propio Alan Greenspan ha mencionado que crisis como la actual sólo se presentan cada 100 años.

Por otro lado, el monto de las pérdidas registradas es inusitado, recordemos que el FMI estimó en 1.3 billones de dólares el 24 de agosto pasado, las pérdidas sufridas por bancos norteamericanos y europeos, antes de que se aprobara el gigantesco paquete de salvataje de Bush y de que se profundizaran los problemas en Europa. Finalmente, cabe destacar que incluso el presidente del Banco Mundial ha expresado la necesidad 
de refundar el sistema financiero internacional, reconociendo que las instituciones multilaterales, de las cuales forma parte dicho banco junto al FMI no funcionan, ni tampoco grupos ad hoc como el G7 y el G8; la solución que propone, sin embargo, sólo apunta a dar mayor legitimidad y cobertura a esos grupos, incorporando a países como: India, Brasil, China, Sudáfrica, Rusia, México y Arabia Saudita; en consecuencia, no constituye una solución verdadera a la ausencia de gobernanza para la globalización financiera.

Las lecciones de la historia económica de América Latina nos enseñan que los impactos de los excesos de la "economía de casino" en que se han convertido los mercados financieros internacionales terminan golpeando muy fuertemente a la región, tanto por los canales financieros como comerciales, a los cuales se suma en la actualidad el flujo de las remesas enviadas por los migrantes, hacia sus familiares en los países de origen.

En esta oportunidad, sin embargo, algunos se preguntan si se ha producido un "desacoplamiento" de la región, debido a los limitados efectos que han sufrido las economías lati- noamericanas en la presente crisis, al menos hasta el momento, debido sobre todo a su positiva posición externa, gracias a los favorables precios de las materias primas que exportan, al menor peso de la deuda externa y a cierta diversificación de sus mercados de exportación ${ }^{8}$.

Esos factores favorables, que tienen un carácter coyuntural, vinculado con la fase ascendente del ciclo económico internacional del período 2003-2007, son diferenciados en los diversos países y están siendo erosionados progresiva y rápidamente por los efectos de la crisis y los cambios que generan en la economía global.

Es fundamental reconocer que la situación externa favorable no ha sido aprovechada por los países latinoamericanos, para reducir la vulnerabilidad externa de tipo estructural que mantienen estas economías, vinculada con sus estructuras productivas y con los patrones de inserción comercial; las recientes caídas en los precios de las materias primas lo evidencian y las exportaciones manufactureras son igualmente frágiles en un contexto de crisis.

Por lo tanto, los "blindajes" que muchos gobiernos latinoamericanos

8. Ver por ejemplo, García Herrero Alicia: ¿Saldrán ganadoras América Latina y Asia de la actual crisis financiera?, Real Instituto Elcano, Julio 15 de 2008. 
¿Otra crisis financiera o un cambio fundamental en el capitalismo financiero?

consideran son los elevados niveles de reservas internacionales acumulados por muchos de ellos, serían de poca ayuda en caso de que la crisis se profundice. Al respecto es interesante destacar que incluso en el caso del Brasil, la economía más grande de la región, que tiene más de $200 \mathrm{mil}$ millones de reservas, hay analistas que consideran que sólo sería un "blindaje de papel crepé", considerando la generalizada liberalización cambiaria y financiera aplicada en los últimos años, unida a la significativa entrada de capitales de corto plazo, en el evento de producirse ataques especulativos o una fuga masiva hacia el dólar.

Los efectos de la crisis en las economías de América Latina estarán determinados tanto por las dimensiones que asuma, como por la fortaleza de su situación macroeconómi$\mathrm{ca}$, de sus cuentas fiscales y de su balanza de pagos, como por su nivel de endeudamiento externo e interno, sus necesidades de financiamiento internacional, así como por su régimen cambiario.
En cualquier caso, se vuelve fundamental el establecimiento de mecanismos regionales que permitan enfrentar, en forma cooperativa y conjunta, las repercusiones comerciales y financieras de la presente crisis. Los esquemas regionales de cooperación financiera, dentro de los cuales se inserta la propuesta del Banco del Sur, asumen una importancia estratégica.

Sin embargo, las primeras respuestas ante la crisis escuchadas en la región, así como los retrasos y problemas que atraviesa la implementación definitiva del Banco del Sur, muestran una vez más, la tendencia a privilegiar las iniciativas unilaterales y los límites para la cooperación regional. Esperemos que la creciente evidencia sobre la magnitud de la crisis y sobre sus efectos devastadores en nuestros países logre modificar esas posiciones.

Quito, 8 de octubre de 2008

9. Reinaldo Gonçalves: "A crise internacional e a América Latina. Com referência especial ao caso do Brasil", Octubre/ 2008. 